\title{
Assess the impacts of climate change on the patterns of rainfall, temperature, and streamflow in the Abelti Watershed of Southwestern Ethiopia
}

BEYENE AKIRSO ALEHU ( $\sim$ beyeneakirso@gmail.com )

Dilla University https://orcid.org/0000-0002-2142-4617

Seble Gizachew Bitana

DU: Dilla University

\section{Research Article}

Keywords: Abelti-watershed, Climate Change, Coefficient of Variation and MK trend

Posted Date: November 24th, 2021

DOI: https://doi.org/10.21203/rs.3.rs-1076340/v1

License: (c) (1) This work is licensed under a Creative Commons Attribution 4.0 International License. Read Full License 


\section{Abstract}

Changes in rainfall, temperature and streamflow (stf) will be one of the most critical factors determining the overall impact of climate change (CC). Thus, in this study we evaluated rainfall(rf), temperature, and stf pattern under changing climate in the Abelti-Watershed (a sub-watershed of upper Omo Gibe basin), Ethiopia. The Representative Concentration Pathway (RCP) scenarios of Hadley Global Environment Model 2-Earth System (HadGEM2-ES) under Coordinated Regional Climate Downscaling Experiment (CORDEX)-Africa database selected for the near (2011-2040), med (2041-2070), and end (2071-2100) periods. Hydrologic Engineering Centers-Hydrologic Modelling System (HEC-HMS) model applied for stf projection. XL-STAT conducts average annual and seasonal if, minimum and maximum temperature (tmin\&tmax), and stf trend tests. Mean seasonal and annual rf and stf variation evaluation taken using the coefficient of variation (CV). Finally, the impact of CC analysis is taken based on the baseline period. The results revealed that the climate model projection is successful for given weather stations. HEC-HMS model showed a satisfactory performance during calibration $(R 2=0.82)$ and validation ( $R 2=0.78)$. The MK trend of tmin\&tmax show significantly increasing; whereas rf and stf show insignificantly decreasing except under RCP8.5. The rf and stf CV analysis indicated less, moderate, and high in the study area. And the future long year average annual if increased by $-3.6 \%,-1.9 \%$ and $-7.7 \%$; temperature $+1.15 \%,+2.2 \%$ and $+4.2 \%$; and stf $-2.9 \%,-0.05 \%$ and $-8.5 \%$ under RCP2.6, RCP4.5 and RCP8.5 respectively. Thus, the decrement in rf and the increment in temperature lead to more evapotranspiration and affect the stf negatively. In conclusion, stf in the Abelti-watershed could significantly decline with adverse consequences for water supplies, agriculture, and ecosystem health for the future. Therefore, this study may contribute to the planning and implementation of sustainable resources development and management strategies and help to mitigate the consequences of CC.

\section{Introduction}

$\mathrm{CC}$ (climate change) is a long-term continuous increase or decrease in climatic variables observed over comparable periods. Climatic variabilities are the types of changes in temperature, rf, and other elements of weather. Despite the annual periodicity in weather patterns, the climate is subject to changes due to the large influence of human activities in the landscape and the composition of the atmosphere (IPCC, 2013). In recent decades, the dramatic development of industrial activities, leads to increasing greenhouse gasses, causes a climatic imbalance on the earth (Mohammad et al., 2014). This, rising greenhouse gas concentrations due to continued gas emissions to the atmosphere from different sources affect climate variables that alter the hydrological cycles (IPCC, 2001). As indicated in the African strategy on CC IPCC (2014), among African countries, Ethiopia is hardest hit by hydro-climatic variabilities, mainly through the frequent occurrence of CCinduced hazards like flooding and droughts.

The Ethiopian government is making efforts to remedy these adverse conditions and has devised coping mechanisms of green economy program throughout the country. Some of these efforts have led to strategies that have induced changes in the attitudes of affected local communities. Despite these, it harms the country in countless ways by increasing existing threats and putting pressure on the environment. In combination, these adversely affects different sectors, like agriculture, ecology, infrastructure, disruption to human activities, loss of property, loss of lives and disease outbreak (UNICEF, 2015). For instance, currently the frequency of flash floods and drought have markedly increased all over Ethiopia and cause physical suffering, economic losses, limit the efficiency of drainage, and disturb the existence of life (Sintayehu, 2015). It is also expected to increase the risk 
in the future because of $\mathrm{CC}$, population densities, deforestation, unsustainable farming practices, limited modernized protection and prevention (UNICEF, 2015 and Simane et al., 2016).

The climate of Ethiopia is mainly controlled by the seasonal migration of the ITCZ (NMSA, 2001) and the complex topography of the country. The main source of moist air is from the Atlantic Ocean, from the SouthWest, the eastern parts of the highlands are more or less rain shadowed (Arnell and Reynald, 1996). The variation of the average annual temperature and if distribution as well as elevation differences can greatly influence the local microclimate (Gebre, 2015), while this difference may be partially influencing the variability and trends in regional if. The hydro-climate variable trend studies in the Blue Nile River basin in Ethiopia have shown a significant increasing trend in both directions (Seleshi \& Zanke, 2004; Tekleab et al., 2013). However, precipitation did not show statistically significant trends both annual and monthly. Current climate variability is already imposing a significant challenge to Ethiopia by deterring the struggle to reduce poverty and sustainable development effort. The World Bank (2010) ranked Ethiopia among the most vulnerable countries in the world to the negative effects of climate change; mainly due to its high dependence on rain-fed agriculture, low adaptive capacity, and a higher reliance on natural resources base for livelihood, among others (NMA, 2007; EPCC, 2015).

In the Omo Gibe River basin, CC poses a huge challenge to the basin and its people (USAID, 2015). This River basin has faced increasingly unpredictable rains, and sometimes the complete unseasonal rains-problems that are linked to CC. According to Abdella and Teshome (2013) traditional rural livelihoods in the area, including agriculture, pastoralism, and agro-pastoralism, are highly sensitive to climate variability and CC because of their close links to the natural environment. Among others, $\mathrm{CC}$ affects climate variables and trends which will have the capacity to alter the hydrological cycles. This leads to unexpected drought, frequent and flash floods, debris flow, and soil erosion are due to hydro-climatic variability and trend pattern variations. Abelti watershed is one of the sub-watersheds of the Omo Gibe River basin and is situated in the upper region of the basin. The area is characterized by densely populated and different public and private sectors are put pressure on the environment related to the basins. In addition to these the existing land and water resources management system of the area is adversely affected by the rapid growth of population, deforestation, poor agricultural practices, geographical location, and topography in combination with low adaptive capacity that entail a high vulnerability to adverse impacts of CC.

The response of a catchment is primarily influenced by physical characteristics and climatic elements. For instance, cascade hydropower schemes, modernized and traditional agricultural practice to meet their needs despite the future effect of $\mathrm{CC}$ on hydro-climatic variables and trends will exacerbate already existing challenges in the catchment (Jaweso, 2019). Moreover, the changing patterns of rf, stf, and temperature amounts will affect the generation of hydroelectric power, the management, and the operation of the dam. However, this issue needs research to design long-lasting solutions for the safety of the population and the natural environment as well. This allows planning appropriate adaptation measures that must be taken ahead of time.

Thus, this study has utilized HadGEM2-ES climate model output scenario under Africa CORDEX database of the three RCPs; (RCP2.6 (Vuuren et al., 2007), RCP4.5 (Clarke et al., 2007), and RCP8.5 (Riahi et al., 2007)) and HECHMS model to assess the impact of CC on the patterns of stf in the Abelti-watershed. RCP is four greenhouse gas concentration (not emissions) trajectories adopted by the IPCC for its fifth Assessment Report (AR5) in 2014. The new RCP framework scenario containing emission, concentration, and land use trajectories and further local details can be considered in it. Hence, compared to the previous scenarios, it has the advantages of 
incorporating the latest information and easily adjusted to new areas. The information will contribute to future planning, managing water resources, working together towards finding lasting solutions, and will act as input for further studies. And also, it may act as a reference for future studies of cc impact on extreme events.

\section{Materials And Methodology}

\section{The study area description}

Abelti-watershed is the main sub-basins of the upper Omo-Gibe River basins and characterized by a complex topography and deeply dissected steep slopes. The altitude of the watershed ranges from 3389 meters above sea level in the Shambu escarpment to an elevation of 1065 meters Abelti gage station. The area of Abeltiwatershed is $15746 \mathrm{~km} 2$ and which is $46.28 \%$ of the total area of the Omo-Gibe River basin. The watershed lies between $7.2^{0} \mathrm{~N} \& 9.5^{0} \mathrm{~N}$ latitude and $36.5^{\circ} \mathrm{E} \& 38.3^{\circ} \mathrm{E}$ longitude (Fig. 1). Most of the watershed from the upper part drains largely cultivated land with less permeable soils. The area falls under the eleven-land use/land cover (LU/LC) types according to Arc-GIS version 10.5. Among these, the moderately cultivated area was found to be largest, followed by bushed shrubbed grassland, intensively cultivated, disturbed high forest, dense mixed high forest, perennial crop cultivation, dense bushland, state farm, waterbody and afro-alpine heath vegetation (Fig. 2). Whereas the soil classification falls under eight major categories. Among these, Orthic Acrisols was found to be largest, followed by Dystric Cambisols, Pellic Vertisols, Chromic Vertisols, Orthic Luvisols, Chromic Luvisols, Lithosols, and Eutric Nitosols (Fig. 3). Also, the climate of the area is characterized by the intermediate climate of tropical sub-humid system. And rf varies from highest $1800 \mathrm{~mm}$ to lowest $900 \mathrm{~mm}$ per annum, and it is monomodal. The mean monthly tmin\&tmax is about $22.5^{\circ} \mathrm{C}$ and $14.5^{\circ} \mathrm{C}$ respectively.

Data types and sources: Seven weather observation stations' daily time-series data of $\mathrm{rf}$ and tmin\&tmax for the year 1985-2014 were collected from the National Meteorological Agency (NMA) of Ethiopia. Daily time series data Abelti gage stf for the year 1990-2006, soil and LU/LC map were collected from Ethiopian Ministry of Water, Irrigation and Electricity (MoWIE). The SRTM Digital Elevation Model (DEM) data with a resolution of one arcsecond (30 meters) was from http://earthexplore r.usgs.gov. Downscaled RCPs (if and tmin\&tmax) data of HadGEM2-ES United Kingdom Met Office Hadley Center, Uk's (Collins et al., 2011) for the period 1971-2100 was obtained from the CORDEX Africa database under CMIP5. The earth system components of the HadGEM2-ES climate model compare well with observations and with other models (Jones et al., 2011). Even this model was used in several CC impact studies in Ethiopia and found consistent with other GCMs (e.g., Niguse and Aleme, 2015; Bhattacharjee and Zaitchik 2015; Urgaya 2016). The RCP is a greenhouse gas concentration (not emissions) trajectories adopted by the IPCC for its fifth Assessment Report (AR5) in 2014. RCP is the latest generation of scenarios, not lie on a fixed set of assumptions related to population growth, economic development, or technological change. And it is spatially explicit and provides information on a global grid at a resolution of approximately $50 \mathrm{~km}$ 's and in which concentration and land use trajectories and further local details can be considered in it. Hence, compared to the previous scenarios it has the advantages of incorporating the latest information and easily adjusted to new areas.

\section{Observed data analyses}

A considerable number of observations are missing in the weather and hydrological time series in the study. Then these temporal and spatial data were screened and pre-processed by Excel spreadsheet and ARC GIS 10.5 
respectively. Missed value of observed if data was filled by Inverse Distance weighted (IDW) method (Chow et al., 1988). This method well considers spatial information than temporal correlations to interpolate (Ramos et al., 2008). A multiple linear regression method was used stf. Then the filled out of observed rf and stf data were subjected to initial quality checks such as consistencies and homogeneity by using XL-STAT software based on Pettitt's test (Pettitt's 1979). The result null hypothesis Ho and Ha according to P-value applied to detect a single change-point or continuous data. As the computed $p$-value is greater than the significance level alpha=0.05, one cannot reject the null hypothesis Ho (homogeneous) and as the computed p-value is less than the significance level alpha=0.05, one cannot reject the null hypothesis $\mathrm{Ha}$ (not homogeneous).

\section{Climate projection data analysis}

Downscaled rf and tmin\&tmax data of RCP2.6 (low emission scenarios), RCP4.5 (medium stabilization emission scenarios), And RCP8.5 (highest emission scenario without CC policy) (van Vurren et al., 2011) were subjected to bias correction. The bias correction procedures are used to minimize the discrepancy between observed and simulated climate variables on a daily time step. so that hydrological simulation are driven by corrected simulated climate data. Seven grid points were selected based on their proximity to the weather station in the watershed. The values of the predicted climate variables are calculated by the IDW method for each climate gage station, to predict their future values are the function of the size of the grids (Sylwia and Emilie, 2014). It relies on the observed climate and local topography features (Charron, 2014) to derive relatively fine spatial resolution of future projections.

In this study, we computed bias correction factors from the statistics of the observed and simulated variables. For rf are determined the correction factors by matching the mean and coefficient of variation (CV) of simulated data with that of observed data (Leander and Buishand, 2007). For temperature, monthly systematic biases were calculated for the baseline period by comparing RCP outputs with the observations (Ho et al., 2012). The nonlinear correction for each daily precipitation $\mathrm{P}$ and a linear bias correction for temperature $\mathrm{T}$ was applied and transformed to a corrected $\mathrm{p}^{*}$ and $\mathrm{T}^{*}$, respectively, using:

$$
p^{*}=a P^{b} a n d T^{*}=a * T+b------------
$$

The coefficient $\mathrm{a}$ and $\mathrm{b}$ are determined iteratively.

After bias correction, RCPs datasets were used for the two time periods in this study; the 1971- 2000 baseline period and the 2011-2100 future period. And the impact analyses were developed for the period of near (20112140), med (2041-2070), and end (2071-2100) in the studied watershed under RCP2.6, RCP4.5, and RCP8.5 respectively. Then rf at a daily time scale is the single most important parameter in hydrological computer simulation models and researchers are often faced with the problem of which interpolation technique to use when determining the spatial distribution of daily if from rain-gage positions. As the rf over a large area is not uniform, the mean depth of if over the study area is determined by the Thiessen polygon method (Subramanya, 2009). In this method, we attempted to allow for non-uniform distribution of gages by providing a weighting factor for every seven gages in the GIS 10.5 window and the mean areal depth of if of observed and the three RCPs were calculated.

\section{Hydrological Model analyses}


The major role hydrologic model is to generate the future stf for the projected climate. Know a day there are many models to simulate rf stf for various reigns and catchment sizes efficiently. For this study HEC-HMS model is selected because the model is applicable in many different size catchments and under considerably different conditions in the world; the same is true in Ethiopia more recently (Sintayehu, 2015). The model input parameters were prepared by a combination of different spatial analyst model tools like; Arc GIS (Zhong, 2014), Arc-Hydro (Li, 2014 and Venkatesh, 2012), and Hec-GeoHMS (USACE, 2000 and Matthew and James, 2013). Basically, by this study, the Snyder unit hydrograph method to model the transformation of excess if into direct stf and deficit (initial loss) and constant loss method were used. The parameters have also been optimized using the optimization tools available in HEC-HMS. To get the optimum parameter values after manually calibrating the model, an automatic trial and error method was applied. The Nelder and Mead optimization method was used than the univariate method because the Nelder and Mead method use downhill simplex to evaluate all parameters simultaneously and adjust once (Feldman, 2000). Each watershed or sub-watershed responds to excess rf to form peak stf and stf volume in the outlet. If events in each sub-basin could be different from other sub-basin events and have their unique output over the watershed. However, there are common "statistical" characteristics of the main processes, which produce the events. The three methods were used to evaluate the model performance during the calibration and validation periods, such as Nash and Sutcliffe simulation efficiency (NSE) (Nash and Sutcliffe, 1970), coefficient of determination (R2), Relative Volumetric Error (RVE) according to their respective range values (Moriasi et al., 2007).

\section{The trend analyses}

The trend analysis was carried out by using the non-parametric Mann-Kendall (MK) (Mann, 1945; Kendall, 1975) in XL-STAT software. MK trend test is a statistical test used to estimate the trend in hydro-climatic time series that has an advantage which can accommodate non-linear trends and data need not be normally distributed (Yue and Wang 2004). Also, it has low sensitivity to abrupt breaks due to inhomogeneous time series (Tabari et al. 2011 and Pingale et al., 2016). To accomplish the analyses, we aggregated time series data of each climate data (rf, tmin\&tmax) to areal mean. Then we checked the trend by graphically and XL-STAT statistical interpretation. As the $p$-value is greater or less than the significance level $a=0.05$ at the confidence level of $99 \%$; $\mathrm{Ho}$, there is no trend; and $\mathrm{Ha}$, there is trend respectively. And also, Kendall's tau or the Z-value was used to analyze either the trend is decreasing or increasing.

\section{The mean Coefficient of Variation (CV) Analyses}

The variability of mean seasonal and seasonal if and stf were analyzed by CV and interpreted. The CV is simply the standard deviation divided by the average annual if times by 100 . According to Hare (1983), \%CV is used to classify the degree of variability of rf events as less, moderate and high. When $\% \mathrm{CV}<20 \%$ it is less variable, $\% \mathrm{CV}$ from $20-30 \%$ is moderately variable, and $\% \mathrm{CV}>30 \%$ is highly variable. For this study, annual, monthly, and seasonal variabilities analysis was taken for Ethiopian local season of Belg/Spring (February March, April, and May), Kiremt/Summer (June, July, August, and September), and Bega/Winter (October, November, December, and January) over Abelti Watershed.

\section{Results And Discussions}


Consistency and Homogeneity: To select representative meteorological stations, checking the homogeneity of group stations is essential. The consistency and homogeneity of rf and stf by using Pettitt's test (Pettitt, 1979) in XL-STAT software show that the observations are from the same population and homogeneous. Due to the computed $p$-value of each mean annual rf and four stf gage stations data is greater than the significance level alpha $=0.05$ at a $99 \%$ confidence interval, one cannot reject the null hypothesis $(\mathrm{HO})$ (Table.1) and the red horizontal broken line is shown in Fig. 4 implies homogeneity of the rainfall station. And which assures that both observations are from the same population and homogeneous. The Thiessen analysis of seven weather stations revealed that five are inside and two are out of the watershed but nearby the watershed. In which the analysis of areal mean if is characterized by bimodal nature. And also, the general rf patterns of the watershed show very high seasonality and exhibit typical characteristics of tropical. Hence, the spatial and temporal distribution of rf governs the amount and intra-and inter-annual variability. In terms of seasons, in most parts of the watershed, rf is heavily concentrated in March, April, and May, and the second heavily rf concentration is in August, September, and October (Fig.5a). In both these seasons, $70-80 \%$ of the total annual rf occurs, and areal mean monthly (amm) rf approximately varies from the highest $200 \mathrm{~mm}$ to the lowest $40 \mathrm{~mm}$ and the average annual if is $1404.70 \mathrm{~mm} /$ year.

Performance of HadGEM2-ES model: It is important to check performance the baseline or observed climate data replicate or not before use. In this study, the simulated ma rf using the HadGEM2-ES model was used and compared with the observed average annual rf of seven stations. Table. 2 illustrates the performance of the climate model in the study checked by root mean square error, observation standard deviation ratio (RSR) which is a root mean square error divide by standard deviation the result is found the range between 0.19 to 0.69 , correlation coefficient (R2) found between 0.89 to 1 and Nash- Sutcliffe efficiency found between 0.83 to 1 , and then the result shows a good agreement and performance. The observed, uncorrected, and corrected control period of the areal mean monthly rf pattern in Fig.5a indicates there is a good agreement between them. Mean monthly rf analysis in the control period indicated that the area characterized monomodal system, high if relatively recorded in August, and low rf recorded in January. The average monthly, tmin\&tmax graphs (Fig.5b) also show a similar pattern with observed climate datasets over the watershed.

HEC-HMS Model: Assessment of CC impact on water resources in a river requires a proper estimation of availability of water and that can only be achieved by hydrological modeling of the basin. In this analysis, sensitive analysis adopted for evaluating the model sensitive parameters were initial loss, constant rate, and peaking coefficient (Cp). The standard lag parameter is estimated from extracted information on the basin and drainage network. Initial loss and peak coefficient were found to be the most sensitive parameters for the simulated streamflow for all the five sub-basins. The model has been calibrated systematically and automatically to optimize and obtain the best possible option. The model well predicts stf depth and peak values in the watershed with the optimized parameters (Table.3). The hydrograph, during the calibration and validation period, is reasonably well in simulating the stf in the study watershed (Fig.6a and b). On the other hand, the simulated flow in these years may have a larger degree of uncertainty since rainfall was highly variable in space and time (Dile et al. 2013). The model results are reasonably accurate for high flow. The objective functions which were used to evaluate the model performance are presented in Table.3. Thus, the statistical test (Willems, 2008) of error function also justifies the validation of the model for simulation of stf hydrograph in the study watershed. The statistical parameter indicates a good model performance in terms of capturing the observed streamflow volume (RVE $=-0.014 \%$ and $0.021 \%$ respectively during calibration and validation period), the pattern

Page $7 / 31$ 
of streamflow hydrographs (NSE=0.82 and 0.78 during calibration and validation period respectively), and coefficient of determination $\left(R^{2}=0.74\right.$ and 0.75 during calibration and validation period respectively).

\section{MK Trend Test result}

A very thorough analysis of the mean annual temperature, rf, and stf trend was checked by Kendall statistics by XL-STAT. This Nonparametric MK statistical test was used to detect trends in rf, tmin\&tmax over the time series aggregated to areal mean. The result of the MK test gives interesting insight about annual tmin\&tmax, If and stf data for the Abelti-catchment according to XL-STAT P-values and Z-value interpretation. As the $p$-value is greater than the significance level $a=0.05 ; \mathrm{Ho}$, there is no trend; and as the P-value is less than the significance level $a=$ $0.05 ; \mathrm{Ha}$, there is a trend. And also, Kendall's tau or the Z-value was used to analyze either the trend is decreasing or increasing.

Rainfall (rf): Changes in if are variable from region to region, and may include changes in the amount, intensity, frequency, pattern, and type. Areal ma observed, baseline and future rf of seven stations over the Abeltiwatershed calculated by Thiessen method and subjected to Mk very thorough analyses in XL-STAT. MK of areal average annual if all period under study in Table.4 result shows a mix of increasing and increasing insignificantly. There is an insignificant increasing trend is detected in observed, end RCP2.6 and three nonoverlapping RCP8.5 periods. While there is insignificant decreasing trend is detected in the periods of baseline, near and med of RCP2.6 and three non-overlapping of RCP4.5. General sense the long year areal average annual future if are decreasing trend pattern under RCP2.6 and RCP4.5 and increasing under RCP8.5. Again, the long year areal average annual if Mk trend graph in Fig.7a shows there is a slightly decreasing trend in both RCP 2.6 and RCP 4.5 and an increasing trend in RCP 8.5. this result is closely much with the report of IPCC (2014) in which if showed both increment and decrement. And the decreasing trend patterns in the southwestern parts of Ethiopia under the latest scenarios of RCPs near and med period supported by EPCC; Gebre and Ludwing (2015). The increment and decrement of if in the future over the study area may lead to unexpected flooding and drought.

Based on the above results, it is of immense importance to discuss the ecological, economic, and social impacts that could result if decreasing rainfall trends continue in the future. And also, this discrepancy in the results may be mainly attributed due to climate variability and watershed characteristics. For rural farmers who have been vulnerable to drought, water stress, and the erratic nature of rainfall, appropriate adaptation strategies should have to be designed and implemented. The vulnerability of rural households might further be aggravated if extreme rainfall episodes continue in the future and consequently result in drought and surface and groundwater losses due to evaporation and overutilization.

Tmin\&tmax: Recorded meteorological data analysis of tmin\&tmax also indicates that increasing trends have been observed almost in all parts of the catchment. The MK test of areal average annual tmin\&tmax shows an increasing trend in observed, baseline, and future three non-overlapping period RCPs scenarios. According to $Z$ and P-value analyses result (Table.4), the average annual tmin\&tmax is a statistically significant increasing trend in the periods of observed, near RCP2.6, near and med RCP4.5, and med and end RCP 8.5. Whereas in the other case tmin\&tmax insignificantly increasing except end period of RCP2.6. On the other hand, in the future long year, the three RCPs average annual tmin\&tmax MK trend graph (Fig.7b and c) show an increasing trend over the catchment. The tmin\&tmax trend increment graphically in RCP8.5 is more than both RCP2.6 and RCP4.5 (Fig.7b 
and c). In general MK statistics of areal average annual, tmin\&tmax is shown an increasing trend and passé the test of significance of a $5 \%$ confidence level, which proved that there was obvious warming up tendency throughout the catchment. The result, in general, implies that the MK-test has shown an increasing trend for the Tmax over the area. And which proved that there was obvious warming up tendency throughout the watershed.

This study in line with, Tekleab et al. (2013) reported the presence of insignificant trends in both monthly and seasonal scale hydro-climatic variables in the majority of climate stations in the Abay basin Ethiopia.

Streamflow (Stf): MK trend test result in Table.4 indicates that all average annual stf had insignificantly decrement trend in baseline and under three non-overlapping periods of RCP 2.6 and RCP 4.5. And there is an insignificant increasing trend pattern in observed and under three non-overlapping periods of RCP8.5. On the other hand, the MK trend graph (Fig.7c) of future long year average annual stf under three RCPs shows that there is an increasing stf trend under RCP 8.5 and decreasing trend under RCP 2.6 and RCP 4.5. The results of MK trend test statistics and graphs (Table.4 and Fig.7c) clearly show the stf trend more related to rf in the area although land use has its influence.

As CC warms the atmosphere, altering the hydrologic cycle, changes to the amount, timing, form, and intensity of precipitation will continue. Another expectation is stf change patterns in watersheds are more related to rf. In some cases, trends in stf are not always consistent with changes in rf (Kiros, 2016). This may be due to the coverage of $\mathrm{rf}$, the effect of human interventions, land use or land cover, soil conditions and types, topographic factor, and environmental modifications.

\section{Coefficient of Variation (CV)}

Rainfall: Rainfall: Changes in rf are variable from region to region, and may include changes in the amount, intensity, frequency, pattern, and type. The CV is simply the standard deviation divided by the average annual rf times by 100 . The overall percentage CV of areal mean seasonal and annual rf analyses was found between $10.1 \%$ and $99.3 \%$ (Table.5). This is an indication of the degree variability of rf events in the study area experiences less, moderate, and high. The average annual CV rf of observed, baseline, and the three nonoverlapping periods under three RCPs was found under $20 \%$ and it is an indication of less variation of if annually. The percentage CV of the observed, baseline, and the three non-overlapping period future RCPs if projection of Bega, Belg, and Kiremt seasons experiences high variability over the watershed. But in the Kiremt seasons' rf of observed, baseline and near period under RCP2.6 CV shows less and moderate variations. Generally, the watershed is more influenced by seasonal rf variations thus for CV is greater than $30 \%$ means that high variability in the seasons. This also indicates that the watershed is vulnerable of the season to CC and vulnerable to hydro-meteorological extremes.

Streamflow: The CV analyses of mean seasonal and annual stf were found between $21.5 \%$ and $86.6 \%$ (Table.5). The degree variation in the case of average annual stf during observed, baseline, and future non-overlapping periods CV is moderately varying in the watershed. Bega and Belg seasons stf CV in all studied periods show high variation (CV greater than 30\%). In the Kiremt season stf CV analysis shows both moderate and high. The large no of CV in the Bega and Belg season stf similar to rf variation in those seasons over the area. The larger no of CVs indicated that the difference of stf among years at the same season was larger, which would put pressure on water management in the catchment. Generally, the study watershed is highly influenced by seasonal variation of rf and stf, which may put pressure on natural and man-made infrastructures. 


\section{Impact of CC analysis}

The impact of climate change on rf, tmin\&tmax, and stf in the Abelti watershed was aggregated. Then the sing representative mean-value was analyzed under RCP2.6, RCP4.5, and RCP8.5 scenarios for three simulations periods (i.e., near: 2011-2040), mid: 2041-2070, and end: 2071-2100).

Rainfall (rf): The future RCPs projections of areal mean monthly if show both increment and decrement in the study watershed (Fig.8a). Respectively 70\% under RCP2.6 and 38\% under RCP8.5 are the largest numbers of mean monthly if increment in October and decrement in March in the near period. The mean monthly largest number increment value in the med period is up to $112 \%$ in the November month and the decrement value is up to $54 \%$ in March month under RCP8.5. Whereas in the end period respectively up to $144 \%$ and $68 \%$ are the largest increment and decrement under RCP8.5. General decrement of mean monthly if revealed in February to May and increment in August to December in three non-overlapping periods of RCP2.6, RCP4.5, and RCP8.5. On the other hand, areal average annual and seasonal if projection in the Table. 6 reveals decrement over the watershed except for the Bega season which shows increment.

tmin\&tmax: The future projections of areal ma and seasonal tmin\&tmax of the study show increment in three RCPs (Fig.8b and c). The mean monthly tmin increment respectively under RCP2.6, RCP4.5, and RCP8.5 in the near period up to $2.1 \mathrm{oc}, 1.7 \mathrm{oc}$, and 2.20c; med period 2.4oc, $2.9 \mathrm{oc}$, and $3.5 \mathrm{oc}$; and end period $2.1 \mathrm{oc}, 2.9 \mathrm{oc}$, and 5.20c. Whereas mean monthly tmax increment respectively under RCP2.6, RCP4.5, and RCP8.5 in the near period up to $1.5 \mathrm{oc}, 1.4 \mathrm{oc}$, and 1.5oc; med period 1.7oc, $2.3 \mathrm{oc}$ and $3.2 \mathrm{oc}$; and end period $1.4 \mathrm{oc}, 2.6 \mathrm{oc}$ and $4.9 \mathrm{oc}$. The variation of future mean monthly tmin is magnificent compared to tmax over the watershed. The tmin\&tmax variation of the end period is greater than both near and med period under the three RCPs. And also, the med period variation is more than the near period under three RCPs. On the other hand, mean seasonal and annual tmin\&tmax in the Table.6 revealed there is an increment tendency over the watershed. The analyses of long-year ma temperature increments over the study are $1.30 \mathrm{c}, 1.9 \mathrm{oc}$, and $3.1 \mathrm{oc}$ under RCP2.6, RCP4.5, and RCP8.5 respectively. The mean seasonal and annual med period of tmin\&tmax increment is more than both near and end period under RCP2.6. However, under RCP4.5 and RCP8.5 more incremental value in end than in the med period. Whereas the analyses of long year mean seasonal temperature increments respectively under RCP2.6, RCP4.5, and RCP8.5 are 1.2oc, 1.7oc, and 2.8oc in the Bega season, 1.6oc, 1.9oc, and 3.2oc in Belg season, and $1.20 \mathrm{c}, 1.9 \mathrm{oc}$, and $3.2 \mathrm{oc}$ in the Kiremt season. In general, average annual and seasonal tmin\&tmax projections show positive increment over the study watershed but in Kiremt seasons increment less compared to the other seasons due to continuous if season for the watershed. The projections of areal average annual tmin\&tmax show increment in three RCPs projections.

Streamflow: Using the capability of the HEC-HMS model for assessing the impact of CC on stf, three RCPs climate projections are simulated for further analysis. The model produced outputs, which were then analyzed to quantify the mean change of stf monthly, seasonal and annual in the study area. However, temperature and rf will affect future stf magnitude monthly, seasonally, and annually. The percentage change of the mean monthly stf result revealed both an increment and decrement (Fig.8d). Generally, three future RCP projections, the mean monthly Stf decrement will be revealed from March to July and increment from August to February. Respectively mean monthly large vale stf increment and decrement projection during the near period in January $73.3 \%$ under RCP2.6 and March 47.0\% under RCP4.5; during the med period in November $135.2 \%$ under RCP 8.5 and May $54.9 \%$ under RCP 4.5; and during end period in the month November $167.1 \%$ under RCP 8.5 and February $63.7 \%$ 
under RCP 4.5. On the other hand, future nonoverlapping annual and seasonal mean stf percentage change of Abelti gage station under three RCPs results is stated in Table.6. Regarding annual stf change in percentage during near period $-0.2 \%,-12.8$ and $+4.4 \%$; during med period $+5.4 \%,-5.3 \%$ and $-0.2 \%$; during end period $-12.8 \%$, $-6.4 \%$ and $-8.4 \%$ respectively under RCP 2.6 , RCP 4.5 and RCP 8.5 compared to the baseline period.

\section{Discussion}

The consistency and homogeneity Pettitt's test (Table.1) XL-STAT analyses of seven weather stations average annual if and stf data in the Abelti watershed indicates ideally possess the property of consistency and homogeneity. In which we prove that the observations are from the same population and homogeneous. And the general areal average if patterns of the watershed show seasonality and exhibit typical characteristics of tropical. Hence, the spatial and temporal distribution of if governs the amount and intra-and inter-annual variability (Kassa, 2015). In terms of seasons, in most parts of the watershed, If is heavily concentrated in June, Julay and August (Fig. 5a). The comparison of areal mean monthly if of both uncorrected and observed period in the controlled period revealed that there is a large value in uncorrected period. However, it indicates a slight underestimation of simulation outputs with bias and a good linear relationship for bias-corrected simulation data. Whereas both controlled period tmin\&tmax of the study revealed that there is comparable value in the observed period. These are also in line with findings by Abdela (2013). The underestimation of the results might be due to insufficient model resolution and topography which provides mechanical uplifting and thermal forcing to air parcels (Li et al., 2016). However, there is a variation of if during, while its performance is within the acceptable range (Table.2). This may be due to individual point regional scale predictors of if variation, which is poorly resolved as compared to temperature (IPCC, 2014). This result reveals that the HadGEM2-ES outputs can be utilized for future projection of rf, tmin\&tmax in the Abelti watershed in Ethiopia.

The calibration and validation result carried out in HEC-HMS 4.5 window for gage station in the study was satisfactory and acceptable. The graph of simulated flow caught the observed flow during calibration and validation period respectively (Fig. 6a and b). This indicates the observed and simulated flow show that the performance of the model in simulating the base flow, rising, and recession limb of the hydrograph is fairly good. And also, the statistical parameter indicates a good model performance in terms of capturing the observed streamflow volume (RVE), the pattern of streamflow hydrographs (NSE), and correlation coefficient (R2) (Table.3). Based on the calibrated parameters and values the model is validated, and the performance is a little bit improved. This is also the simulated flow in both periods may have a larger degree of uncertainty since if was highly variable in space and time (Dile et al. 2013).

According to the Z-values, areal average if of baseline, and future RCP2.6 and RCP4.5 of the watershed generally shows insignificantly decreasing trend but RCP8.5 insignificantly increasing trend. And based on the results (Table.4 and Fig. 7a, b, c and d) it is of immense importance to discuss the ecological, economic, and social impacts that could result if decreasing rainfall trends continue in the future. This discrepancy in the results may be mainly attributed due to climate variability and watershed characteristics. For rural farmers who have been vulnerable to drought, water stress, and the erratic nature of rainfall, appropriate adaptation strategies should have to be designed and implemented. The vulnerability of rural households might further be aggravated if extreme rainfall episodes continue in the future and consequently result in drought and surface and groundwater losses due to evaporation and overutilization. The mean annual tmin\&tmax of the observed period and near period under RCP2.6, med period under RCP4.5 and med and end period RCP8.5 show a significant increasing 
trend. Whereas in the remaining period there are an insignificant increasing trend according to Mk of $\mathrm{p}$-value (Table.4). The result, in general, implies that the MK-trend test has shown an increasing trend for the tmin\&tmax over the area. The trend increment of tmin shows more tmax over the watershed. In which the long-year mean annual tmin\&tmax MK trend inspection; RCP8.5 trend increment greater than from both RCP4.5 and RCP2.6; and RCP4.5 greater than RCP2.6. And which proved that there was obvious warming up tendency throughout the watershed. This study in line with, Tekleab et al. (2013) reported the presence of insignificant trends in both monthly and seasonal scale hydro-climatic variables in the majority of climate stations in the Abay basin. On the other hand, the trend test on average annual stf result revealed that insignificantly decreasing trend in all studied period except under RCP8.5. The decreasing trend of average annual stf over study indicates there is a high tendency of temperature and evapotranspiration. And these finding is similar with finding by Negash, (2013) and Shank, (2017) in the basin of Rift-Valley Lakes basin in Ethiopia.

The future RCPs projections of areal mean monthly, seasonal and annual rf show both increment and decrement in the study watershed (Fig. 8a, Table.6). The decrement of rf in annual, Kiremt and Belg may lead the shortage of future water availability in the area, which is essential for agricultural purposes and hydropower. And the increment of Bega season if over the study may lead to unexpected hydrological extremes. There is also a risk of a downstream cascade hydropower dam in the basin. Annual rf shows slight increment and decrement over the catchment. This result is in line with the study by Abdella (2013) in the area by using old climate model scenarios of REMO. This discrepancy in the results may be mainly attributed due to climate variability (Kassa, 2014) and watershed characteristics. And also, these study results are in good agreement with similar studies performed for the Ethiopian regions for annual and seasonal scales (e.g. Niguse and Alemu 2015; Li et al. 2016). The increase or decrease in precipitation might be due to the combined effects of seasonal movement of the Inter-Tropical Convergence Zone (ITCZ), local land surface heating, and topographic forcing (Li et al. 2016).

The mean monthly tmax\&tmin of three RCPs projection for future non-overlapping periods revealed in Fig. 8b and $\mathrm{c}$ expected positive increment in the watershed. The observed period average monthly tmax analysis revealed a positive increment between $+0.16{ }^{\circ} \mathrm{C}$ to $+1.2{ }^{\circ} \mathrm{C}$ in the study watershed. The average annual and seasonal tmax deviation stated in Table.6 shows a positive increment in three RCPs projections over three nonoverlapping periods in the study area. When we inspect the figure the mean monthly tmin\&tmax positive increment in RCP2.6 is greater than in RCP4.5 and RCP8.5. In a general sense average monthly tmin\&tmax of the study revealed a positive increment in three RCPs in the three-non-overlapping periods. When we come to the seasonal case in the study the Belg and Kiremt season tmin\&tmax increment is more than the other seasons in three RCPs under three non-overlapping periods in the area. Annually air temperature is expected to increase in all months in both RCP scenarios. Increasing air temperature was however much higher in RCP8.5 and was associated with the fact that RCP8.5 is a higher greenhouse gas emission scenario with a higher degree of global warming. And also, the maximum amount of temperature change from RCP8.5 is since RCP8.5 produces more greenhouse gas as compared to RCP4.5 and RCP2.6, which is medium and low in greenhouse gas production (Riahi et al., 2011). In general, average annual and seasonal tmin\&tmax projections show positive increment over the study watershed but in Kiremt seasons increment less compared to the other seasons due to continuous if season for the watershed. The projections of areal average annual tmin\&tmax show increment in three RCPs projections. According to the result close agreement with the study by Abdella (2013) in the area by using old climate scenarios of REMO. In the 2080s of RCP 2.6, RCP 4.5, and RCP 8.5, the change in monthly mean tmin\&tmax magnificent compared to near and 2050 `s for the catchment. The result generally shows clear

Page $12 / 31$ 
agreement with the indication of EPCC (2015) over southwestern parts of Ethiopia future the area experiences rise in tmin\&tmax.

The watershed is more influenced by seasonal if variations thus for $\mathrm{CV}$ is greater than $30 \%$ means that high variability in the seasons. This also indicates that the watershed is vulnerable of the season to $\mathrm{CC}$ and vulnerable to hydro-meteorological extremes. The larger no of CVs indicated that the difference of stf among years at the same season was larger, which would put pressure on water management in the catchment. Generally, the study watershed is highly influenced by seasonal variation of if and stf, which may put pressure on natural and manmade infrastructures.

The increase in temperature accelerates the evapotranspiration process which further influences the rf amount and ultimately contributes to the modification of seasonal stf. The change of mean monthly, seasonal and annual stf results showed that the future increment in both directions over the watershed (Table.6 and Fig. 8d). Regarding the study, positive and negative direction increments in local seasonal streamflow in the watershed under three RCPs. The three non-overlapping periods' future Bega seasons stf projection result shows an increment over the watershed compared to baseline under three RCPs. Whereas the Belg and Kiremt seasons stf projection show decrement under three RCPs scenarios of non-overlapping period and which corresponds to rf projection in the area. Overall, in the Bega season, a bigger percentage change increment is recorded, which may lead to unexpected extreme floods. Again, the bigger negative percentage stf value in the Belg season will lead to the shortage of water demand for agriculture and hydropower management in the basin. Hence the future monthly and seasonal great variation of stf leads a significant effect to domestic use and irrigation activity in the area as well as hydropower projects downstream. These projected effects of possible future climate change would significantly affect many hydrologic systems, which in turn affect the water availability and runoff, and the flow in rivers. The maximum reduction of flow can be anticipated in the Belg season as compared to the other seasons. This may be attributed to the increase in average temperature and potential-evapotranspiration. The projected precipitation under RCP4.5 and RCP8.5 scenarios shows that precipitation may significantly decrease in the near-term and mid-term periods, respectively. This decline of streamflow may cause an acute shortage of irrigation water owing to increasing demands for fresh water in the future periods.

\section{Conclusions}

The assessment of the CC impact over hydro-climatic variables and trends represents an important issue for resources management. The observational records and climate projections provide abundant evidence that hydro-climatic variables and trends are dramatically changing and have the potential to be strongly impacted by CC. Impact studies with hydrological models on the effects of CC are important as they can indicate how the hydrological processes are likely to be affected and how strong they are going to be affected in the future in the area. This is especially relevant for policymakers, those charged with the responsibility of selecting appropriate adaptation measures. HEC-HMS model predicted the measured stf provided satisfactory in both calibration and validation according to performance evaluation (Table.3 and Fig.6). The MK test, on the other hand, demonstrated that in the case of if is statistically insignificant (null hypothesis accepted) at a $5 \%$ significant level over the study area. For air temperature, the MK test indicated that there is a statistically significant and insignificant increasing trend over the catchment. Mk trend test of stf shows an increment in both directions insignificantly. The MK test at $5 \%$ significant level indicated that long year ma tmin\&tmax are statistically increasing trend over the catchment, whereas, rf and stf show both decreasing and increasing in three RCPs 
scenarios projections. In annual air temperature is expected to increase in all months in three RCP scenarios. Increasing air temperature was however much higher in RCP8.5 and was associated with the fact that RCP8.5 is a higher greenhouse gas emission scenario with a higher degree of global warming.

In general, in the Abelti watershed mean areal monthly, seasonal and annual stf has shown both increment and decrement in three RCPs scenarios. Increment and decrement of monthly, seasonal and annual stf under three RCPs but its projection change increment of 2080 `s greater than in near and med. However, more increment and decrement mean stf percentage change recorded in the seasons of Bega and Belg in three projections. Hence, the increase and decrease in flow volume in the basin may have a significant contribution to the sustainability of existed and undergoing water development projects. This study found that the Abelti-catchment is very sensitive to climatic change in terms of temperature, rf, and stf. For this study results, are highly much because from rf and stf analysis for future period increase under RCP 2.5 and 4.5 for the med period. The study output is relevant because supported by the two investigators Chaemiso et.al, (2016) and Abdella and Teshome (2013) in the study area and by EPCC (2015). An increase in the magnitude of extreme if in the study area may have a significant negative effect on the sustainability of existed agriculture practice (UNICEF, 2015), the life of the community, and hydropower development projects downstream. Moreover, it will lead to unexpected flood hazards and drought on community settlers. However, a precaution of mitigation and preparedness measures ought to be taken for possible flooding in the floodplain area of the river basin and downstream.

\section{Recommendations}

Knowing the monthly, seasonal, and annual simulated long-term average annual rf, temperature, and stf components in the future is useful to recommend better alternative and complementary action. Keeping in view, the threats to the survival of the Abelti watershed, the following steps are recommended are sought.

The models and model outputs used in this study possessed a certain level of uncertainty. The model simulation considered land-use changes remain constant for the future time horizons and single GCM emission scenarios although it is not true in the actual case. Hence, the results of this research should be taken carefully and be considered as an indicative prediction of the future and further researches should be extended by considering the future land-use changes, other climatic variables and different GCM outputs.

The status of the study area environment in recent years has been known to be seriously adjusted by man's technology coupled with the glaring climatic change which together greatly increase the risk of high extreme events. The study points to upcoming water resource problems so that mitigation and adaptation strategies can be made ahead. The study will also assist policymakers in decision-making on irrigation development in the watershed.

\section{Declarations}

\section{Acknowledgments}

We would like to acknowledge the Ethiopian Ministry of Water Resource, Irrigation and Electricity; National Meteorological Agency; and International Water Management Institute for providing the necessary data.

Conflict of Interest: The Authors have no conflicts of interest to disclose.

Page $14 / 31$ 


\section{References}

Abdella Kemal, (2013). The effect of climate change on water resources potential of Omo-Gibe Basin, Ethiopia. Ph.D. dissertation.

Arnell, N.W. \& Reynard, N.S. (1996). The Effects of Cc Due to Global Warming on River Flows in Great Britain. Journal of Hydrology. 183 (3-4), pp 397-424. https://doi.org/10.1016/0022-1694(95)02950-8

Bhattacharjee, P.S. and Zaitchik, B.F. (2015). Perspectives on CMIP5 Model Performance in the Nile River Headwaters Regions. International Journal of Climatology. 35, 4262-4275. https://doi.org/10.1002/joc.4284.

Chaemiso SE, Abebe A, Pingale SM. (2016). Assessment of the impact of climate change on surface hydrological processes using SWAT: a case study of Omo-Gibe River basin. Ethiopia Model Earth System Environment. http://doi.org/10.1007/s40808-016-0257-9.

Charron, I. (2014). A Guidebook on Climate Scenarios: Using Climate Information to guide Adaptation Research and Decisions. Ouranos, 86p. hg.

Chow V.T., Maidment D.R., and L.W. Mays (1988). Applied Hydrology, Mc Graw Hill Book Company. ISBN 0-07010810-2.

Clarke, L., J. Edmonds, H. Jacoby, H. Pitcher, J. Reilly, R. Richels (2007). Scenarios of Greenhouse Gas Emissions and Atmospheric Concentrations. Sub-report 2.1A of Synthesis and Assessment Product 2.1 by the U.S. Climate Change Science Program and the Subcommittee on Global Change Research. Department of Energy, Office of Biological \& Environmental Research, Washington, 7 DC., USA, 154 pp.

Collins, W. J., Bellouin, N., Doutriaux-Boucher, M., Gedney, N., et al. (2011). Development and evaluation of an Earth-System model - HadGEM2, Geosci. Model Dev., 4, 1051-1075, https://doi.org/10.5194/gmd-4-1051-2011, $\underline{2011 .}$

Dile YT, Berndtsson R, Setegn SG (2013) Hydrological Response to Climate Change for Gilgel Abay River, in the Lake Tana Basin - Upper Blue Nile Basin of Ethiopia. PLoS ONE 8(10):

e79296. https://doi.org/10.1371/journal.pone.0079296

Ethiopian Panel on climate change (EPCC) (2015). First Assessment Report, Summary of Reports for Policy Makers, Published by the Ethiopian Academy of Sciences

Feldman AD (2000). Hydrologic Modeling System HEC-HMS. Technical Reference Manual. US Army Corps of Engineers (USACE). Hydrologic Engineering Center, HEC. Davis, CA, USA.

F. F. Snyder (1938). “Synthetic Unit Graphs," Transactions American Geophysics Union, Vol. 19, 1938, pp. 447-45

Gebre SL, Ludwig F (2015). Hydrological Response to Climate Change of the Upper Blue Nile River Basin: Based on IPCC Fifth Assessment Report (AR5). Journal of Climatology Weather Forecasting 3:

121. https://doi.org/10.4172/2332-2594.1000121 
Hare, F.K. (1983) Climate and Desertification: A Revised Analysis. World Climate Applications Programme. World Meteorological Organization, Geneva, 149 p.

Ho CK, Stephenson DB, Collins M, Ferro CAT, Brown SJ. (2012) Calibration strategies: a source of additional uncertainty in climate change projections. Bulletin of the American Meteorological Society 93:21-26.

IPCC (2001). Climate change 2001: The Third Assessment Report of Intergovernmental Panel on Climate Change. Cambridge University Press, UK.

IPCC (2007) Climate Change (2007): the physical science basis. In: Contribution of Working Group I to the Fourth Assessment Report of the Intergovernmental Panel on Climate Change. IPCC

IPCC (2013). Summary for Policymakers. In: Climate Change 2013: The Physical Science Basis. Contribution of Working Group I to the Fifth Assessment Report of the Intergovernmental Panel on Climate Change [Stocker, et al (eds.)]. Cambridge University Press, Cambridge, United Kingdom and New York, NY, USA, pp. 1-30, http://dx.doi.org/10.1017/CB09781107415324.004.

IPCC (2014) Climate change: Synthesis report. Contribution of working groups I, II and III to the fifth assessment report of the Intergovernmental Panel on Climate Change [Core Writing Team, R.K. Pachauri and L.A. Meyer (Eds.)]. IPCC, Geneva, Switzerland.

Jaweso, Abate, Bauwe, \& Lennartz. (2019). Hydro-Meteorological Trends in the Upper Omo-Ghibe River Basin, Ethiopia. Water, 11(9), 1951. MDPI AG. http://dx.doi.org/10.3390/w11091951

Jones, C. D., Hughes, J. K., Bellouin, N., Hardiman, S. C., Jones, G. S., Knight, J., et al., (2011): The HadGEM2-ES implementation of CMIP5 centennial simulations, Geosci. Geosci. Model Dev., 4, 543-570. https://doi.org/10.5194/gmd-4-543-2011, 2011

Kassa Fekadu (2015). Ethiopian Seasonal Rainfall Variability and Prediction Using Canonical Correlation Analysis (CCA), Earth Sciences. Vol. 4, No. 3, 2015, pp. 112-119. https://doiorg/10.11648/j.earth.20150403.14

Kefyalew A (1994). The Climatology of Drought over parts of Ethiopia and their Impacts on Crop Production with Special Reference to the Impact of Drought on the Production of Barley and Maize. PhD thesis (Climatology), University of Nairobi, Kenya.

Kendall, M.G. (1975). Rank Correlation Methods. 4th Edition, Charles Grifin, London.

Kiros, G., Shetty, A. \& Nandagiri, L. (2016). Analysis of variability and trends in rainfall over northern Ethiopia. Arab J Geosci 9, 451 (2016). https://doi.org/10.1007/s12517-016-2471-1

Leander R, Buishand TA. (2007) Resampling of regional climate model output for the simulation of Extreme River flows. Journal of Hydrology 487-496.

Li, L., Li, W., Ballard, T., Sun, G., \& Jeuland, M. (2016). CMIP5 model simulations of Ethiopian Kiremt-season precipitation: current climate and future changes. Climate Dynamics, 46(9-10), 2883-

2895. https://doi.org/10.1007/s00382-015-2737-4

Page 16/31 
$\mathrm{Li}$, Z. (2014). Watershed modeling using arc hydro based on DEMs: a case study in Jackpine watershed. Environ System Research 3, 11. https://doi.org/10.1186/2193-2697-3-11

Mann, H.B. (1945). Nonparametric Tests against Trend. Econometrica, 13, 245-259. http://dx.doi.org/10.2307/1907187.

Matthew J. Fleming, James H. Doan, Feb 2013. Hec-GeoHMS Geospatial Hydrological Modelling Extension Version 10.1 User Manual. USACE institute for water resources (CEIWR-HEC) 609 second street. Davis, CA $95616-$ 4687.

Mohammad Reza Farzaneh, Saeid Eslamian, Zahra Samadi S. and Aboulfazl Akbarpour, (2014). An appropriate GCM to investigate climate change impact. International journal of hydrology science and technology. 2(1):34-

47. https://doi.org/10.1504/IJHST.2012.045938

Moriasi DN, Arnold JG, Van Liew MW, Bingner RL, Harmel R.D, Veith TL. (2007) Model evaluation guidelines for systematic quantification of accuracy in watershed simulations. Trans. ASABE 50, 885-900.

http://doi.org/10.13031/2013.23153.

Nash, J.E. and Sutcliffe, J.V. (1970). River Flow Forecasting through Conceptual Models Part I-A Discussion of Principles. Journal of Hydrology, 10, 282-290. http://dx.doi.org/10.1016/0022-1694(70)90255-6

Niguse A, Aleme A (2015). Modeling the impact of climate change on production of Sesame in western zone of Tigray, Northern Ethiopia. Journal of Climatology and Weather Forecasting 3:150. https://doi.org/10.4172/23322594.1000150

NMA (2007). National adaptation program of action of Ethiopia (NAPA). Final draft report. NMA, Addis Ababa NMSA (2001). Initial National Communication of Ethiopia to the United Nation Framework Convention on Climate Change (UNFCCC). National Meteorological Services Agency, Addis Ababa, Ethiopia.

Pettitt, A.N. (1979) A Non-Parametric Approach to the Change-Point Problem. Applied Statistics, 28, 126-135. https://doi.org/10.2307/2346729

Pingale SM, Khare D, Jat MK, Adamowski J. (2016). Trend analysis of climatic variables in an arid and semi-arid region of the Ajmer District, Rajasthan, India. J Wat Lan Dev. 28(1):3-18.

Ramos-Calzado, P., Gomez-Camacho, J., Perez-Bernal, F. and Pita-Lopez, M.F. (2008). A Novel Approach to Precipitation Series Completion in Climatological Datasets: Application to Andalusia. International Journal of Climatology, 28, 1525-1534. https://doi.org/10.1002/joc. 1657

Riahi, Gruebler \& Nakicenovic (2007). Scenarios of long-term socio-economic and environmental development under climate stabilization. Technological Forecasting and Social Change, Volume 74, 7, pp. 887-935. https://doi.org/10.1016/j.techfore.2006.05.026

Seleshi Y, Zanke U (2004). Recent changes in RF and rainy days in Ethiopia. International Journal of Climatology., 24 (8): 973-983. https://doi.org/10.1002/joc.1052 
Sintayehu LG, (2015). Application of the HEC-HMS Model for Streamflow Simulation of Upper Blue Nile River Basin. Hydrology Current Research 6:199. https://doi.org/10.4172/2157-7587.1000199

Simane, B., Beyene, H., Deressa, W., Kumie, A., Berhane, K., \& Samet, J. (2016). Review of Climate Change and Health in Ethiopia: Status and Gap Analysis. The Ethiopian journal of health development = Ya'ltyopya tena lemat mashet, 30 (1 Spec Iss), 28-41.

Subramanya K. (2009). Engineering Hydrology. 7 West Patal Nagar, New Delhi 110 008: Tata McGraw.

Sylwia Trzaska and Emilie Schnarr, (2014). A Review of Downscaling Methods for climate change Projections: (PLACE) Indefinite Quantity Contract Core Task Order (USAID Contract No. AID-EPP-I-0006-00008, Order Number AID-OAA-T0-11-00064).

Tabari, H., Marofi, S., Aeini, A., Hosseinzadeh-Talaee, P. and Mohammadi, K. (2011). Trend Analysis of Reference Evapotranspiration in the Western Half of Iran. Agricultural and Forest Meteorology, 151, 128-136. https://doi.org/10.1016/j.agrformet.2010.09.009

Teshome Seyum and Manfred Koch, 2013. Swat-hydrological modelling and simulation of inflow to cascade reservoir of semi-ungaged Omo-Gibe River basin, Ethiopia: PH.D. dissertation Kassel University ICWRER 2013.

Tekleab. S, Mohamed. M, Uhlenbrook. S (2013). Hydro-climatic trends in the Abay/Upper Blue Nile basin, Ethiopia. Physics and Chemistry of the Earth. 61-62 (2013) 32-42. https://doi.org/10.1016/j.pce.2013.04.017

UNICEF (2015). Situation reports, news, analysis, evaluations, assessments, maps, infographics and more on Ethiopia: Floods. (Southern Somali, Southern Oromia, and the lowlands in South Omo Zone in SNNPR).

US Army Corps of Engineers (USACE) (2000). Hydrologic Modeling System HEC-HMS Technical Reference Manual. Hydrologic Engineering Center, Davis.

Urgaya ML (2016). Modeling the impacts of climate change on chickpea production in Adaa Woreda (East Showa Zone) in the semi-arid central Rift valley of Ethiopia. J Pet Environ Biotechnol 7:

288. https://doi.org/10.4172/2157-7463.1000288

van Vuuren, D.P., Edmonds, J., Kainuma, M. et al (2011). The representative concentration pathways: an overview. Climatic Change 109, 5 (2011). https://doi.org/10.1007/s10584-011-0148-z

van Vuuren, D.P., den Elzen, M.G., Lucas, P.L. et al. (2007). Stabilizing greenhouse gas concentrations at low levels: an assessment of reduction strategies and costs. Climatic Change 81, 119-159 (2007). https://doi.org/10.1007/s10584-006-9172-9

Venkatesh Merwade (2012). Watershed and Stream Network Delineation using Arc Hydro Tools: School of Civil Engineering, purdel Purdue University Merwade@purdue.edu

Willems, P. (2008). A time-series tool to support the multi-criteria performance evaluation of rainfall-streamflow models. Environmental Modeling and Software. Corpus ID:

31180597. https://doi.org/10.1016/j.envsoft.2008.09.005 
World Bank (2010). World Development Report (2010). Development and Climate Change. Washington, DC. (C) World Bank. https://openknowledge.worldbank.org/handle/10986/4387 License: CC BY 3.0 IGO."

Yue S, Wang C. (2004) The Mann-Kendall Test modified by effective sample size to detect trend in serially correlated hydrological series. Water Resources Management 18:201-218.

Zaroug M.A.H., E.A.B. Eltahir, and F. Giorgi (2014). Droughts and floods over the upper catchment of the Blue Nile and their connections to the timing of EINino and La Nina events. Hydrology Earth System. Sci., 18, 1239-2014.

Zhong li (2014). Watershed modeling using arc hydro based on DEMs: a case study in Jackpine watershed. Environmental Systems Research2014. 3:11. https:/doi.org/10.1186/2193-2697-3-11.

\section{Tables}

Table.1 Homogeneity test result of average annual rf and stf.

\begin{tabular}{|c|c|c|c|c|c|c|c|c|}
\hline \multicolumn{2}{|l|}{ Wolkite } & Limu & Assandabo & Woliso & Shambu & Jimma & Gedo & Abelti-Stf \\
\hline \multicolumn{2}{|c|}{ Pettitt's test } & $\ddot{\mathrm{u}}$ & $\ddot{\mathrm{u}}$ & $\ddot{\mathrm{u}}$ & $\ddot{\mathrm{u}}$ & $\ddot{\mathrm{u}}$ & $\ddot{\mathrm{u}}$ & $\ddot{\mathrm{u}}$ \\
\hline $\mathrm{K}$ & 61 & 61 & 54 & 56 & 105 & 58 & 85 & 48 \\
\hline $\mathrm{t}$ & 2003 & 1993 & 1990 & 1998 & 1993 & 1988 & 2005 & 2001 \\
\hline p-value & 0.66 & 0.66 & 0.786 & 0.756 & 0.106 & 0.723 & 0.28 & 0.45 \\
\hline alpha & 0.05 & 0.05 & 0.05 & 0.05 & 0.05 & 0.05 & 0.05 & 0.05 \\
\hline interpretation & Ho & Ho & Ho & Ho & Ho & Ho & Ho & Ho \\
\hline
\end{tabular}

Table.2 Comparison of average monthly observed and bias corrected rf of controlled period

\begin{tabular}{llllllll}
\hline Station & Wolkite & Woliso & Shambu & Ass. & Jimma & Limu & Gedo \\
\hline RSR & 0.43 & 0.27 & 0.63 & 0.31 & 0.29 & 0.19 & 0.47 \\
R $^{2}$ & 0.89 & 1.0 & 0.99 & 0.98 & 0.99 & 1.0 & 0.977 \\
Nash & 0.83 & 1.0 & 0.999 & 0.97 & 0.99 & 1.0 & 0.97 \\
\hline
\end{tabular}

Table.3 HEC-HMS model performances evaluation in the Abelti gage station 


\begin{tabular}{|c|c|c|c|c|c|c|}
\hline \multicolumn{4}{|c|}{ Stf depth (mm) } & \multicolumn{3}{|c|}{ Peak stf (m3/s } \\
\hline Modeling type & Observed & Simulated & & Observed & Simulated & \\
\hline calibration & 8108.7 & 8112.61 & & 1810.7 & 1809.7 & \\
\hline validation & 2279.36 & 2282.2 & & 1296.2 & 1293.8 & \\
\hline Modeling type & & RMS Error & Average Abs Error & NSE & RVE (\%) & $\mathrm{R}^{2}$ \\
\hline calibration & & 13.5 & 11.2 & 0.74 & -0.014 & 0.82 \\
\hline validation & & 5.8 & 9 & 0.75 & 0.021 & 0.78 \\
\hline
\end{tabular}

Table.4 XL-STAT MK trend test results of average annual rf, tmax, tmin and Stf 


\begin{tabular}{|c|c|c|c|c|c|c|c|c|c|c|}
\hline Variable & & period & test & $\mathrm{Zs}$ & $\mathrm{s}$ & $\operatorname{Var}(\mathrm{s})$ & $\mathrm{p}$ & Alpha & Sen's & Interpretation \\
\hline $\mathrm{rf}$ & & Observed & Annual & 0.07 & 29 & 3141.67 & 0.62 & 0.05 & 1.37 & Ho \\
\hline & & Baseline & & -0.14 & -63 & 3141.67 & 0.27 & 0.05 & -2.84 & Ho \\
\hline & RCP & near & & -0.25 & -109 & 3141.67 & 0.05 & 0.05 & -9.62 & Но \\
\hline & 2.6 & med & & -0.01 & -5 & 3141.67 & 0.94 & 0.05 & -0.38 & Но \\
\hline & & end & & 0.04 & 19 & 3141.67 & 0.75 & 0.05 & 2.72 & Но \\
\hline & RCP & near & & -0.07 & -31 & 3141.67 & 0.59 & 0.05 & -2.45 & Но \\
\hline & 4.5 & med & & -0.05 & -21 & 3141.67 & 0.72 & 0.05 & -2.31 & Ho \\
\hline & & end & & -0.13 & -57 & 3141.67 & 0.32 & 0.05 & -3.67 & Ho \\
\hline & $\mathrm{RCP}$ & near & & 0.14 & 59 & 3141.67 & 0.3 & 0.05 & 3.59 & Но \\
\hline & 8.5 & med & & 0.1 & 43 & 3141.67 & 0.45 & 0.05 & 4.56 & Но \\
\hline & & end & & 0.04 & 19 & 3141.67 & 0.75 & 0.05 & 1.62 & Но \\
\hline
\end{tabular}

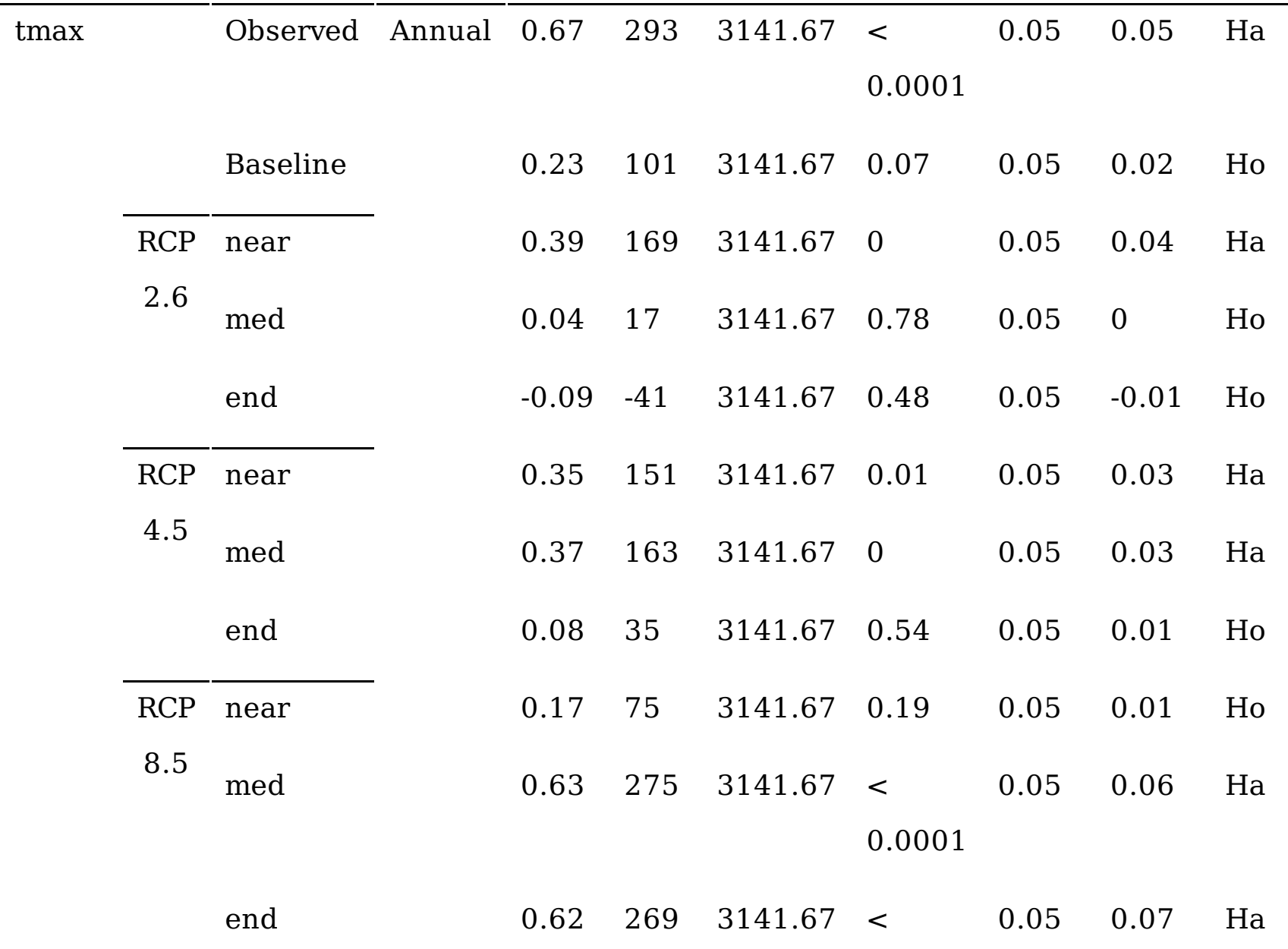




\begin{tabular}{|c|c|c|c|c|c|c|c|c|c|c|}
\hline \multirow[t]{14}{*}{ tmin } & & Observed & Annual & 0.56 & 243 & 3141.67 & $<$ & 0.05 & 0.03 & $\mathrm{Ha}$ \\
\hline & & & & & & & \multicolumn{4}{|l|}{0.0001} \\
\hline & & \multicolumn{2}{|l|}{ Baseline } & 0.22 & 97 & 3141.67 & 0.09 & 0.05 & 0.02 & Ho \\
\hline & $\mathrm{RCP}$ & \multicolumn{2}{|l|}{ near } & 0.35 & 151 & 3141.67 & 0.01 & 0.05 & 0.03 & На \\
\hline & 2.6 & \multicolumn{2}{|l|}{ med } & 0.07 & 29 & 3141.67 & 0.62 & 0.05 & 0.01 & Ho \\
\hline & & \multicolumn{2}{|l|}{ end } & 0 & -1 & 3141.67 & 1 & 0.05 & 0 & Ho \\
\hline & $\mathrm{RCP}$ & \multicolumn{2}{|l|}{ near } & 0.5 & 219 & 3141.67 & 0 & 0.05 & 0.05 & $\mathrm{Ha}$ \\
\hline & 4.5 & \multicolumn{2}{|l|}{ med } & 0.41 & 179 & 3141.67 & 0 & 0.05 & 0.03 & $\mathrm{Ha}$ \\
\hline & & \multicolumn{2}{|l|}{ end } & 0.06 & 27 & 3141.67 & 0.64 & 0.05 & 0.01 & Ho \\
\hline & $\mathrm{RCP}$ & \multicolumn{2}{|l|}{ near } & 0.22 & 97 & 3141.67 & 0.04 & 0.05 & 0.02 & Ho \\
\hline & 8.5 & \multicolumn{2}{|l|}{ med } & 0.6 & 263 & 3141.67 & $<$ & 0.05 & 0.07 & $\mathrm{Ha}$ \\
\hline & & & & & & & \multicolumn{3}{|l|}{0.0001} & \\
\hline & & \multirow{2}{*}{\multicolumn{2}{|c|}{ end }} & 0.64 & 277 & 3141.67 & $<$ & 0.05 & 0.07 & Ha \\
\hline & & & & & & & \multicolumn{3}{|l|}{0.0001} & \\
\hline \multirow[t]{10}{*}{ Stf } & & Observed & Annual & 0.12 & 32 & 1625.3 & 0.44 & 0.05 & 2.1 & Ho \\
\hline & & \multicolumn{2}{|l|}{ Baseline } & -0.12 & -51 & 3141.7 & 0.37 & 0.05 & -1.71 & Ho \\
\hline & $\mathrm{RCP}$ & \multicolumn{2}{|l|}{ near } & -0.26 & -111 & 3141.7 & 0.05 & 0.05 & -3.38 & Ho \\
\hline & 2.0 & \multicolumn{2}{|l|}{ med } & -0.01 & -3 & 3141.7 & 0.97 & 0.05 & -0.11 & Ho \\
\hline & & \multicolumn{2}{|l|}{ end } & -0.01 & -5 & 3141.7 & 0.94 & 0.05 & -0.05 & Ho \\
\hline & $\mathrm{RCP}$ & \multicolumn{2}{|l|}{ near } & -0.09 & -41 & 3141.7 & 0.48 & 0.05 & -1.53 & Ho \\
\hline & 4.5 & \multicolumn{2}{|l|}{ med } & -0.06 & -27 & 3141.7 & 0.64 & 0.05 & -0.61 & Ho \\
\hline & & \multicolumn{2}{|l|}{ end } & -0.12 & -53 & 3141.7 & 0.35 & 0.05 & -1.38 & Ho \\
\hline & $\mathrm{RCP}$ & \multicolumn{2}{|l|}{ near } & 0.14 & 59 & 3141.7 & 0.3 & 0.05 & 1.49 & Ho \\
\hline & 8.5 & \multicolumn{2}{|l|}{ med } & 0.15 & 65 & 3141.7 & 0.25 & 0.05 & 1.94 & Ho \\
\hline
\end{tabular}


Table.5 Average CV of seasonal and annual rf and stf in percentage (\%)

\begin{tabular}{|c|c|c|c|c|c|c|c|c|c|c|}
\hline \multicolumn{11}{|c|}{$\mathrm{rf}$} \\
\hline \multirow[t]{2}{*}{ Seasons } & \multicolumn{4}{|c|}{ RCP 2.6} & \multicolumn{3}{|c|}{ RCP 4.5} & \multicolumn{3}{|c|}{ RCP 8.5} \\
\hline & Observed & near & med & end & near & med & end & near & med & end \\
\hline Annual & 10.1 & 14.1 & 16.1 & 18 & 16.1 & 18.1 & 13.7 & 13.3 & 19.5 & 15.3 \\
\hline Bega & 78 & 72.9 & 85.2 & 81.4 & 83.3 & 89.1 & 90.3 & 72.4 & 85.4 & 78.7 \\
\hline Belg & 40.3 & 69.6 & 88.6 & 72.3 & 68.7 & 81 & 73.2 & 75.7 & 79 & 81.9 \\
\hline Kiremt & 17 & 27.1 & 35.2 & 30.9 & 32.9 & 32 & 32.9 & 31.6 & 39.1 & 32.5 \\
\hline \multicolumn{11}{|c|}{ Stf } \\
\hline Annual & 29.9 & 25 & 28.3 & 26.6 & 27 & 29.2 & 21.5 & 23.6 & 32.5 & 28.5 \\
\hline Bega & 46.7 & 57.9 & 86.6 & 64.6 & 58.6 & 79 & 85.1 & 58.9 & 75.3 & 81.1 \\
\hline Belg & 69.3 & 58.7 & 65.6 & 50.8 & 64.4 & 75.4 & 53.1 & 60.6 & 62.7 & 71.2 \\
\hline Kiremt & 29.4 & 31.2 & 35.4 & 28.1 & 31.6 & 31.9 & 29.1 & 29.2 & 35.9 & 36.7 \\
\hline
\end{tabular}

Table.6 Average seasonal and annual change of rf, tmax, tmin and stf compared to base period 
Rf change in \%

\begin{tabular}{l|rrrrrrrrrr}
\hline seasons & \multicolumn{3}{c}{ RCP 2.6 } & \multicolumn{3}{c}{ RCP 4.5 } & \multicolumn{3}{c}{ RCP 8.5 } \\
\cline { 2 - 10 } & near & med & end & near & med & end & near & med & end \\
\hline Annual & -1 & -10.7 & 0.8 & 1.3 & -4.6 & -2.3 & -10.2 & -7.8 & -5 \\
Bega & 29.5 & 21.8 & 18.3 & 16 & 45 & 41.7 & 6.9 & 42.5 & 81.5 \\
Belg & -12.9 & -23.6 & 0.9 & -6.8 & -28.6 & -24.5 & -30.1 & -28 & -37.4 \\
Kiremt & -0.2 & -9.8 & -2.1 & 2.7 & -1.1 & 1.1 & -3.5 & -6.3 & -3.7 \\
\hline
\end{tabular}
tmax change in ${ }^{\circ} \mathrm{C}$

\begin{tabular}{l|ccccccccc}
\hline Annual & 1.1 & 1.5 & 1.2 & 1.2 & 2.0 & 2.3 & 1.5 & 2.8 & 4.8 \\
Bega & 0.8 & 1.2 & 1.1 & 0.9 & 1.5 & 1.8 & 1.2 & 2.3 & 3.9 \\
Belg & 1.7 & 2.0 & 1.5 & 1.3 & 2.3 & 2.6 & 1.7 & 3.2 & 4.9 \\
Kiremt & 0.8 & 1.3 & 1.0 & 1.3 & 2.2 & 2.4 & 1.6 & 3.0 & 4.9 \\
\hline
\end{tabular}

tmin change in ${ }^{\circ} \mathrm{C}$

\begin{tabular}{l|rrrrrrrrr}
\hline Annual & 1.2 & 1.5 & 1.3 & 1.2 & 2.1 & 2.4 & 1.4 & 3.0 & 4.9 \\
Bega & 1.1 & 1.4 & 1.4 & 1.2 & 2.1 & 2.4 & 1.3 & 3.0 & 4.9 \\
Belg & 1.2 & 1.5 & 1.3 & 1.3 & 2.1 & 2.4 & 1.4 & 3.0 & 4.9 \\
Kiremt & 1.2 & 1.5 & 1.2 & 1.2 & 2.0 & 2.3 & 1.5 & 2.9 & 5.0 \\
\hline
\end{tabular}

Stf change in \%

\begin{tabular}{l|rrrrrrrrr}
\hline Annual & -0.2 & -12.8 & 4.4 & 5.4 & -5.3 & -0.2 & -12.8 & -6.4 & -6.4 \\
\cline { 2 - 10 } Bega & 59.4 & 62.1 & 51 & 48.5 & 103.9 & 84.7 & 33.4 & 91 & 91 \\
Belg & -16.4 & -26.5 & 7.2 & -7.9 & -36.3 & -32.1 & -38.1 & -32.2 & -32.2 \\
Kiremt & 0.2 & -15.7 & -3.3 & 6.6 & -3.8 & 5.2 & -5.8 & -6 & -6 \\
\hline
\end{tabular}


Figures

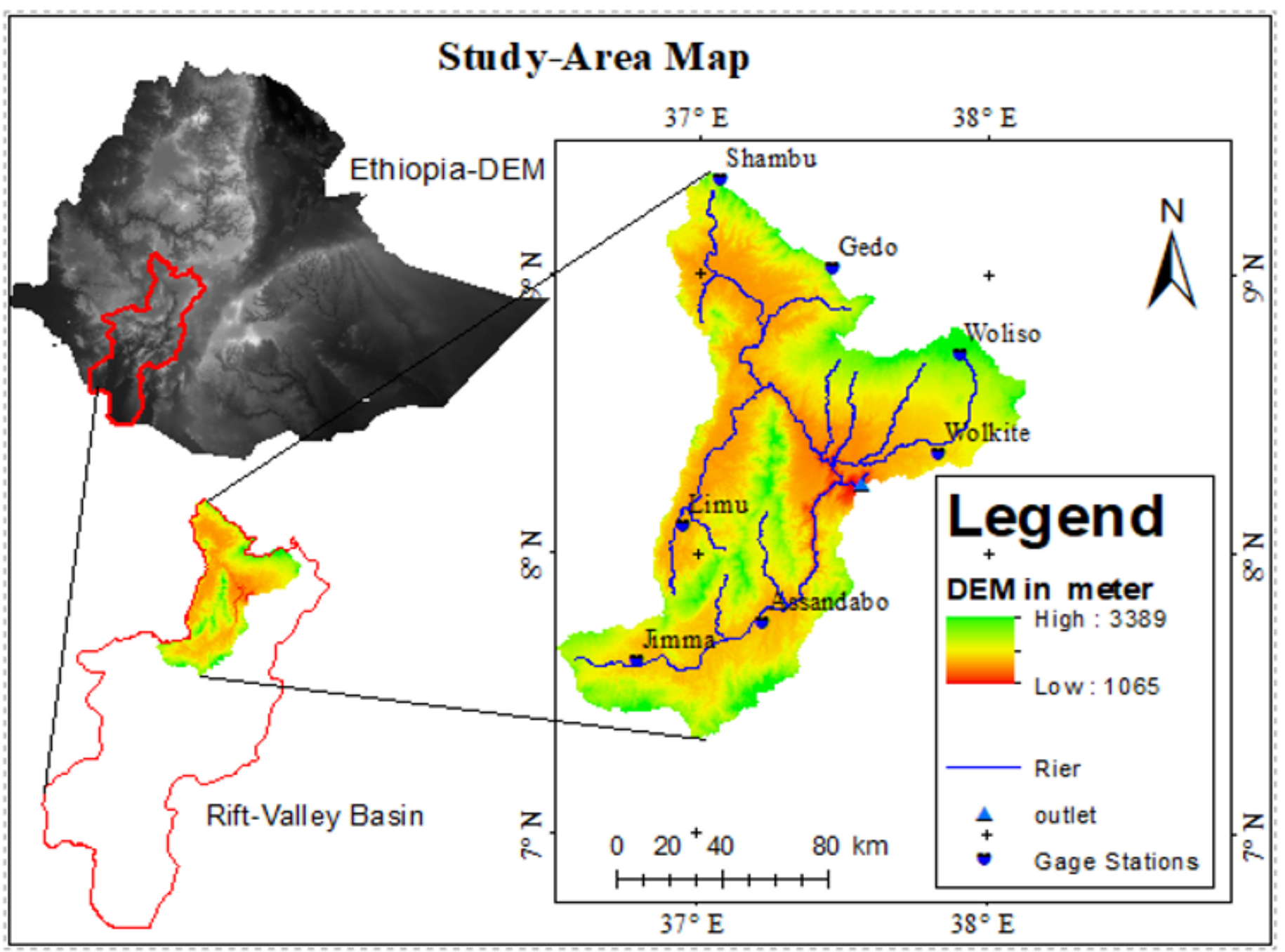

Figure 1

Location of the study area 


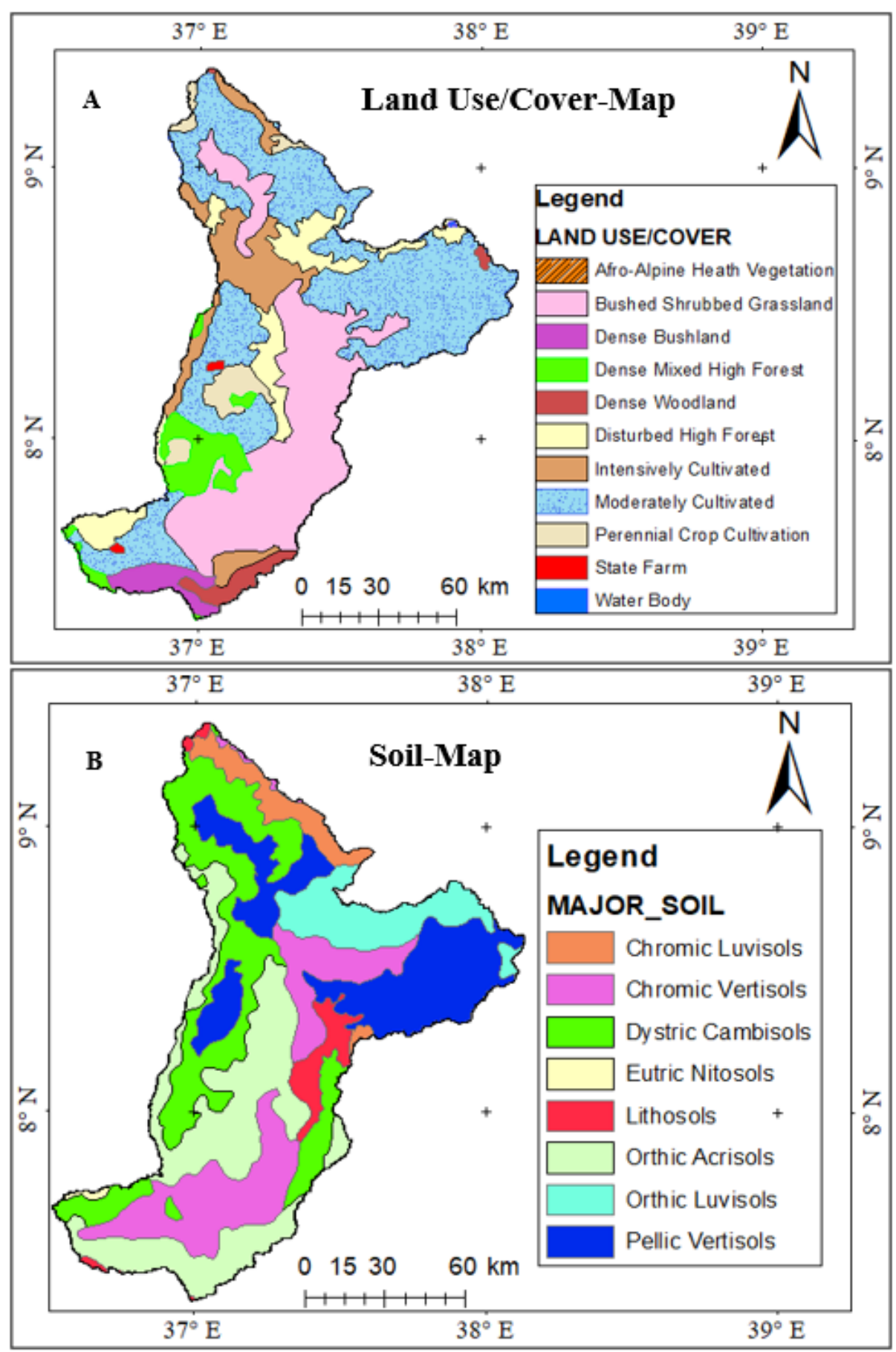

Figure 2

Land use or land cover and Soil map of the study 


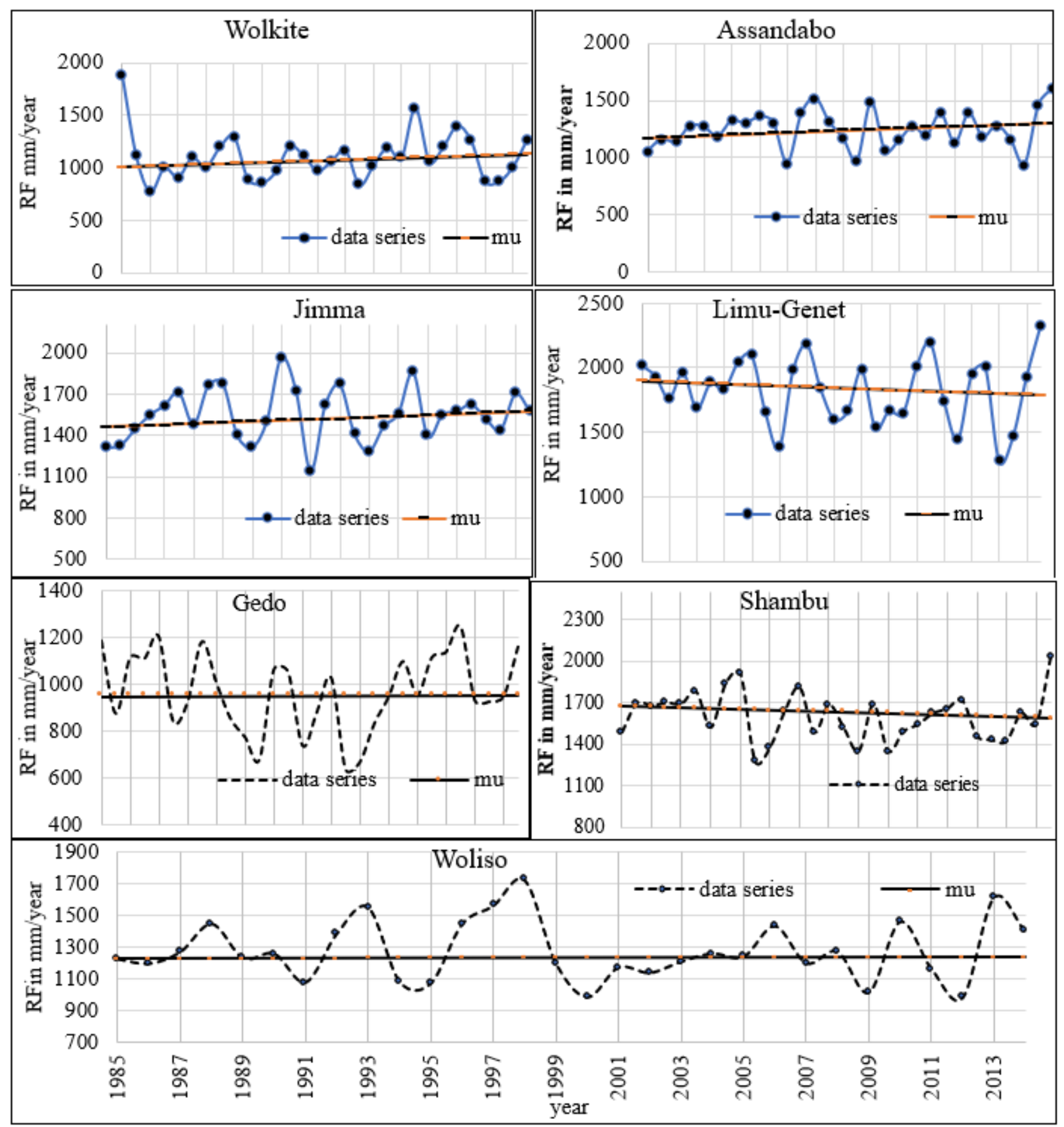

Figure 3

Homogeneity Pettit's test of annual if 


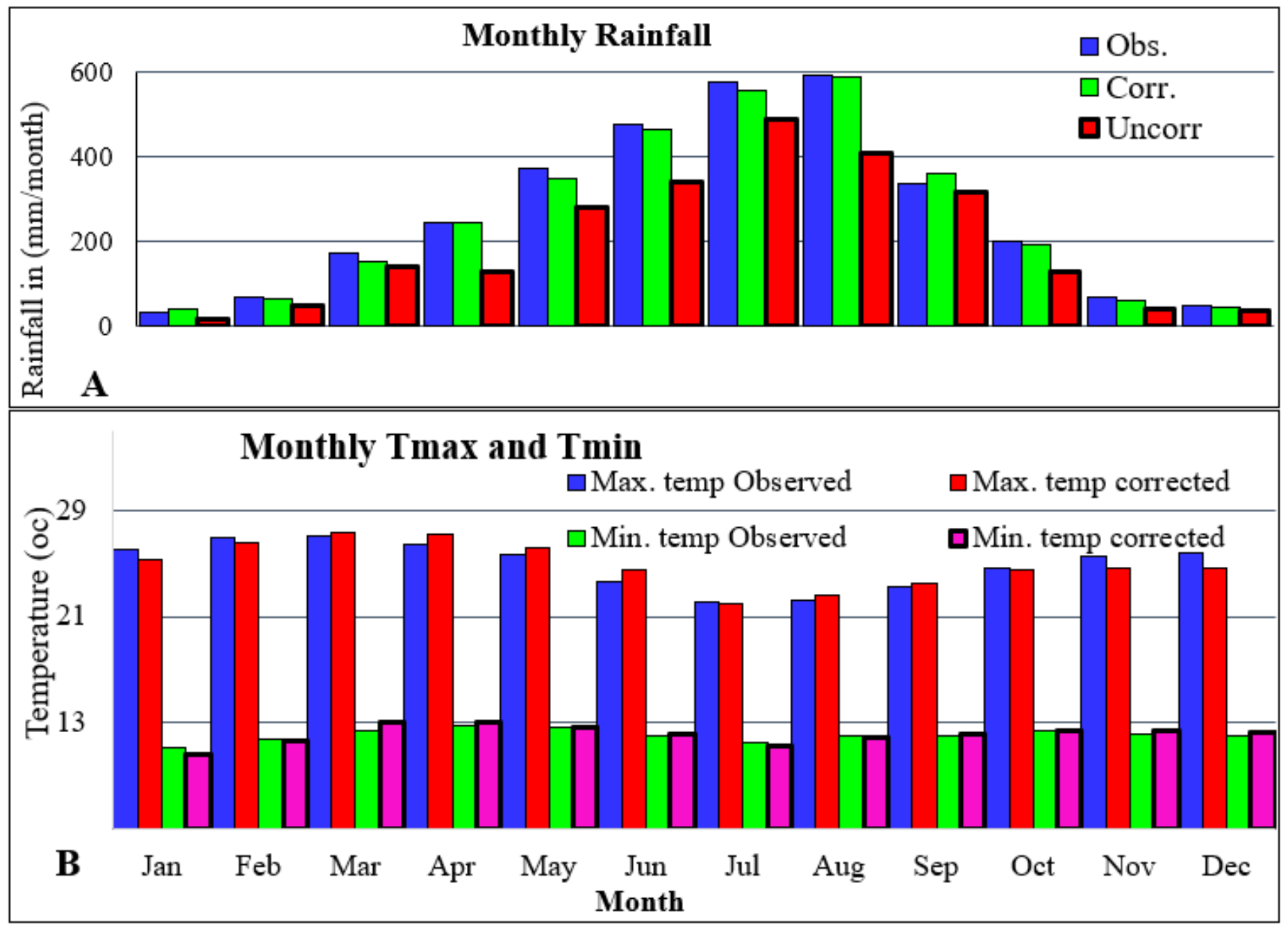

Figure 4

Areal average monthly RF and tmin\&tmax of observed, corrected and uncorrected 


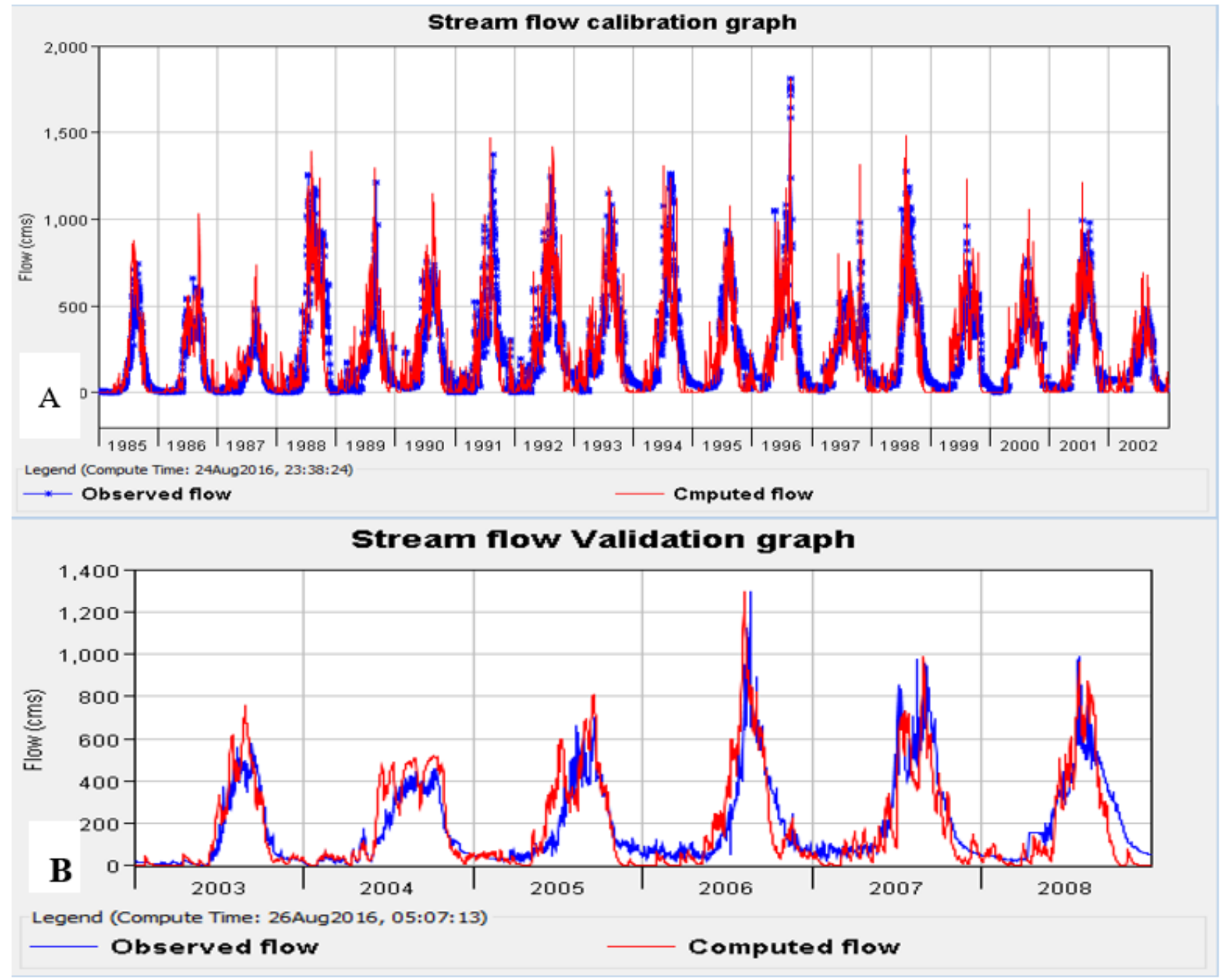

Figure 5

Calibration and validation graphs 


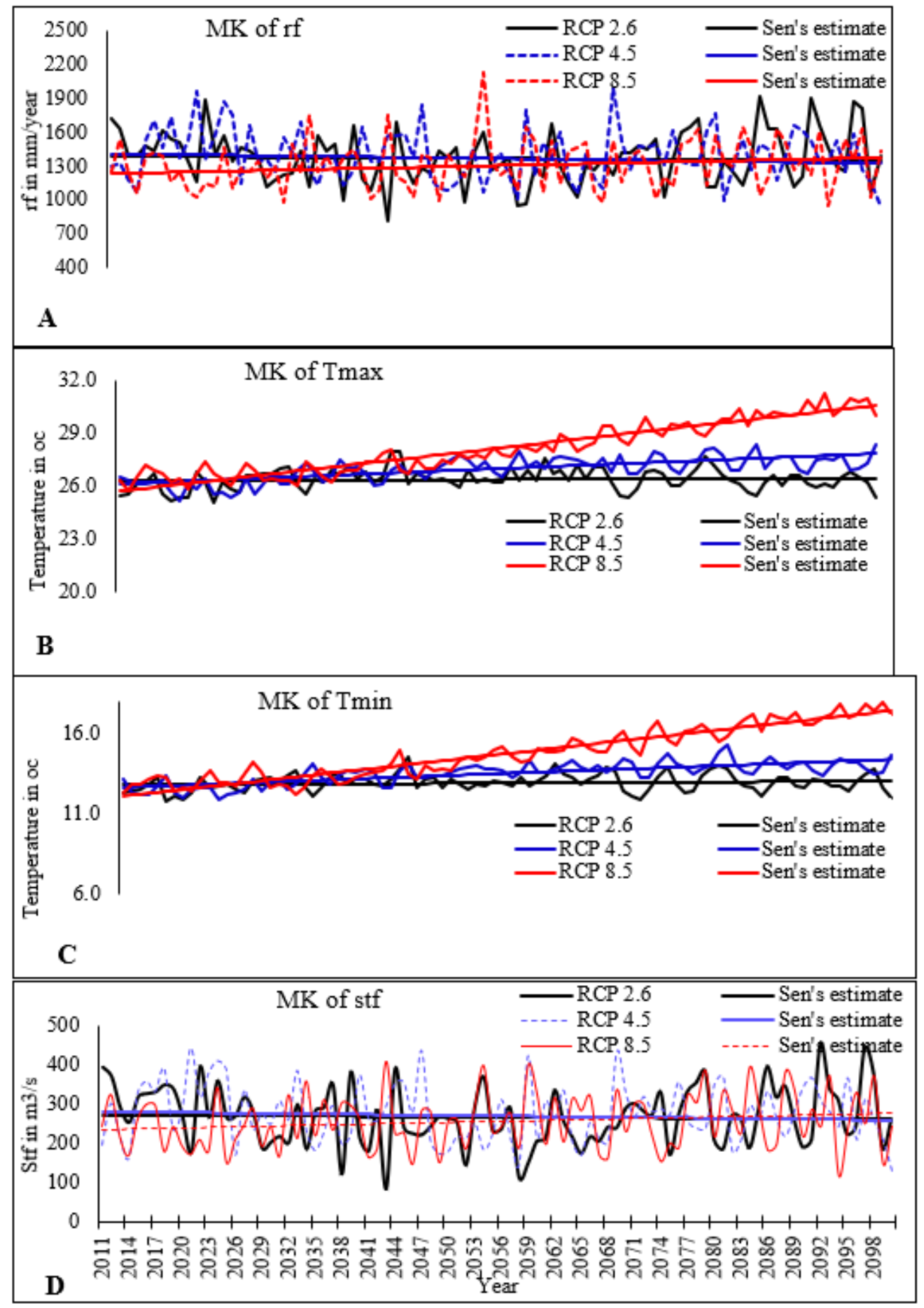

Figure 6

MK trend graphs of average annual rf, tmin, tmax and stf 


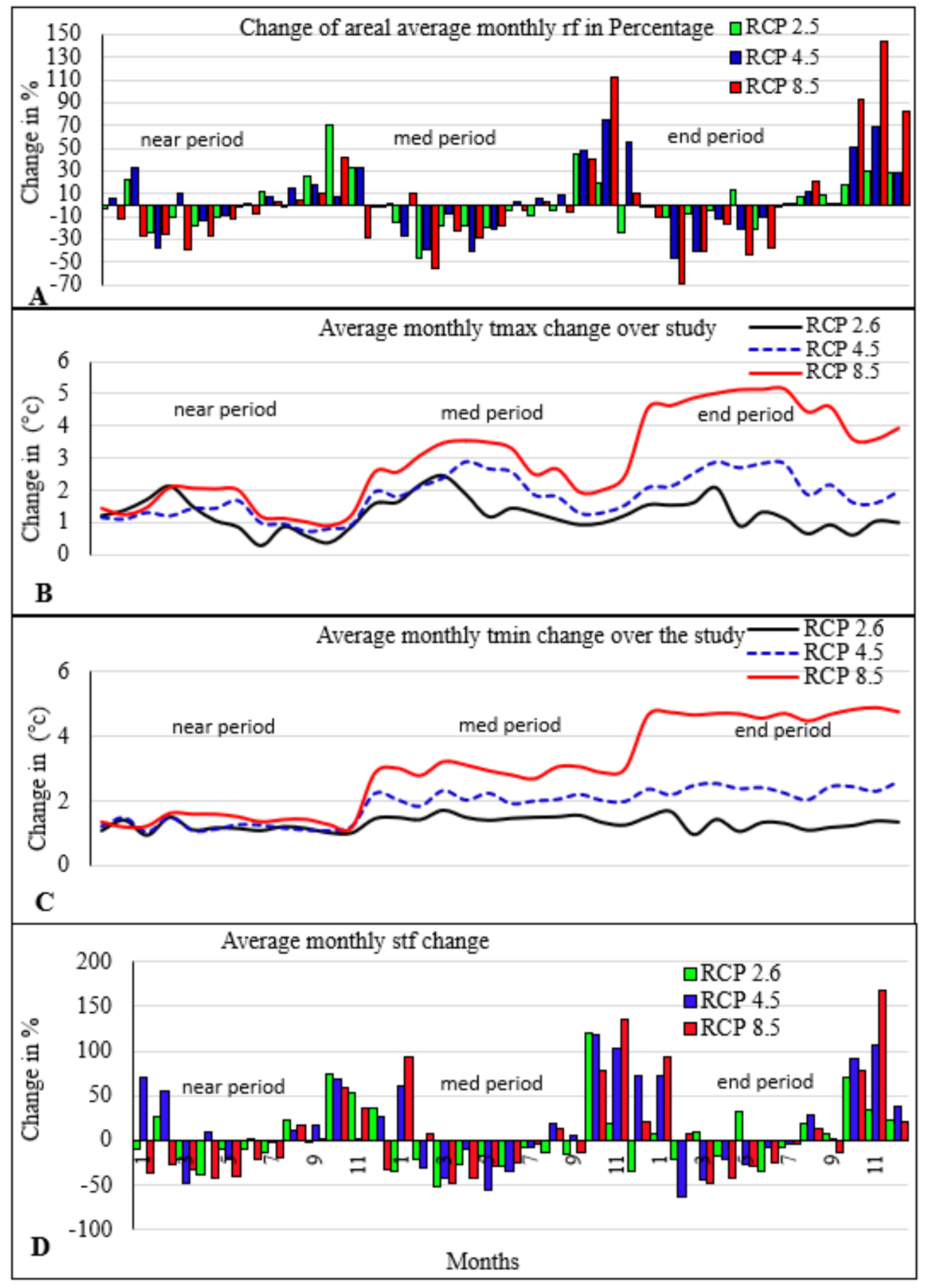

Figure 7

Relative change of average monthly $\mathrm{rf}$, tmax, tmin and stf in the period of near, med and end under three RCPs to the baseline period 